\title{
ПРОФЕССИОНАЛЬНОЕ ВЫГОРАНИЕ И ЭМПАТИЯ МЕДИЦИНСКИХ РАБОТНИКОВ ПРОТИВОТУБЕРКУЛЕЗНЫХ ДИСПАНСЕРОВ
}

\author{
(С) Удалова Т.Ю. ${ }^{1}$, Мордык А.В. ${ }^{2}$, Резниченко И.С. ${ }^{1}$, Ароян А.P. ${ }^{2}$, Руденко С.А. ${ }^{3}$, Батищева Т.Л. ${ }^{4}$ \\ ${ }^{1}$ Кафедра практической психологии Омского государственного педагогического университета, \\ Омск; ${ }^{2}$ кафедра фтизиатрии и фтизиохирургии Омского государственного медицинского \\ университета, Омск; ${ }^{3}$ Клинический противотуберкулезный диспансер № 4; Омск, \\ ${ }^{4}$ Клинический противотуберкулезный диспансер, Омск \\ E-mail: anna-aroyan@yandex.ru
}

Деятельность работников медицинской сферы и эффективность выполнения своих профессиональных обязанностей зависят от многих параметров, немаловажным является психологическое состояние самого специалиста. В отечественной литературе проблемам работников медицинской отрасли посвящен ряд работ, но основной тренд исследований направлен на изучение факторов, связанных с эмоциональным выгоранием, которое, как правило, приводит к профессиональной деформации. Профессиональная деформация, в свою очередь, негативно влияет на профессиональную деятельность. В настоящей работе представлены результаты исследования компонентов профессионального выгорания и уровня эмпатийных тенденций медицинских работников противотуберкулезных диспансеров. Врачи в отличие от санитарок и медицинских сестер характеризуются большей величиной редукции личностных достижений и меньшим уровнем эмпатии.

Ключевые слова: профессиональное выгорание, эмпатия, врач, медсестра, санитарка, противотуберкулезное учреждение.

\section{PROFESSIONAL BURNING OUT AND EMPATHY OF HEALTH WORKERS OF ANTITUBERCULAR CLINICS Udalova T.Yu. ${ }^{1}$, Mordyk A.V. ${ }^{2}$, Reznichenko I.S. ${ }^{1}$, Aroyan A.R. ${ }^{2}$, Rudenko S.A. ${ }^{3}$, Batishcheva T.L. ${ }^{4}$ \\ ${ }^{1}$ Department of Practical Psychology of Omsk State Pedagogical University, Omsk; ${ }^{2}$ Department of Phthisiology and Phthisiosurgery of Omsk State Medical University, Omsk; ${ }^{3}$ Clinical Antitubercular Clinic N 4, Omsk; \\ ${ }^{4}$ Clinical Antitubercular Clinic, Omsk}

Activities of the medical workers and effectiveness of performing their professional duties is dependent on many factors, not the least is the psychological state of a specialist. In the domestic literature the problems of medical workers in the industry a number of papers, but the underlying trend research aims to study factors related to emotional burnout, which usually leads to a professional deformation. Professional deformation, in turn, adversely affects the professional activity. In the real work results of research of components of professional burning out and level the empatiynykh of tendencies of health workers of antitubercular clinics are presented. Doctors unlike nurses and nurses are characterized by the bigger size of a reduction of personal achievements and smaller level of empathy, also, raised empatiynost promotes increase of depersonalization of the personality.

Keywords: professional burning out, empathy, doctor, nurse, nurse, TB facility.

Деятельность работников медицинской сферы и эффективность выполнения ими своих профессиональных обязанностей зависят от многих параметров, немаловажным является психологическое состояние самого специалиста $[7,11]$. В отечественной литературе проблемам работников медицинской отрасли посвящен ряд работ, но основной тренд исследований направлен на изучение факторов, связанных с эмоциональным выгоранием, которое, как правило, приводит к профессиональной деформации [6]. Профессиональная деформация, в свою очередь, негативно влияет на профессиональную деятельность [4].

Под эмпатией понимается совокупность отношений к объекту, объединяющая родственные понятия, такие как признание, помощь, понимание [2]. Иными словами под термином эмпатия подразумевается переживание эмоций другого человека или когнитивный инструмент, основанный на интеллектуальном понимании переживаний другого человека [16].

Но на сегодняшний день нет единого системного подхода к изучению выгорания, который бы описывал данный феномен со всех сторон. К тому же преимущественно изучались профессиональные деформации врачей без учета медсестер и санитарок, которые составляют основной костяк медицинских работников. В настоящей работе предпринята попытка выявить взаимосвязь эмпатии с уровнем эмоционального и профессионального выгорания среди медсестер, санитарок и врачей противотуберкулезных диспансеров. 
Уровни «выгорания»

\begin{tabular}{|l|c|c|c|}
\hline \multirow{2}{*}{ Субшкала } & \multicolumn{3}{|c|}{ Уровень } \\
\cline { 2 - 4 } & низкий & средний & высокий \\
\hline Эмоциональное истощение & $0-16$ & $17-26$ & 27 и больше \\
\hline Деперсонализация & $0-6$ & $7-12$ & 13 и больше \\
\hline Редукция личных достижений & $31-0$ & $38-32$ & 39 и больше \\
\hline
\end{tabular}

Цель исследования: выявить особенности эмоционального и профессионального выгорания медицинских работников противотуберкулезных диспансеров и влияние на его развитие эмпатии.

\section{МАТЕРИАЛЫ И МЕТОДЫ ИССЛЕДОВАНИЯ}

Исследование проходило на базе двух Казенных учреждений здравоохранения Омской области (КУЗОО), Клинического противотуберкулезного диспансера (КПТД) и Клинического противотуберкулезного диспансера № 4 (КПТД № 4). Протестировано 150 медицинских сотрудников: 17 врачей (средний возраст $38,5 \pm 4,2$ года, средний стаж $6 \pm 2,2$ года), 79 медсестер (средний возраст $41,2 \pm 7,1$ года, средний стаж $8,4 \pm 1,2$ года),

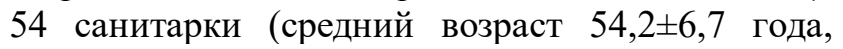
средний стаж 9,2 $\pm 3,8$ года) по двум методикам.

В качестве первой методики выбран опросник «Профессиональное (эмоциональное) выгорание (MBI)», авторы К. Маслач и С. Джексон, в адаптации для медицинских работников Н.Е. Водопьяновой. В опроснике содержится 22 утверждения об эмоциях, связанных с профессиональной деятельностью [3]. Тест состоит из трех субшкал (эмоциональное истощение, деперсонализация и персональные достижения). Интерпретация результатов производится на основании сравнения полученных оценок по каждой из шкал с данными разработчиков. Так, для российской выборки нормативные показатели среднего уровня составляют значения, представленные в таблице 1.

В качестве второй использована методика «Способность медицинского работника к эмпатии», автор И.М. Юсупов [13]. Данная методика предполагает ответы на 36 утверждений. Для упрощения интерпретации данных баллы переводились в единицы, соответствующие процентному соотношению эмпатийных тенденций. Чем выше процентное соотношение, тем ярче выражено проявление эмпатии.

Статистическая обработка результатов осуществлялась при помощи программного пакета Statistica 6.0. Для множественных сравнений данных использовался ранговый критерий Краскела-Уоллиса. Для оценки различий между двумя независимыми выборками использовался U-критерий Манна-Уитни. Для определения силы и направления корреляционной связи между шкалой эмпатии и уровнями профессионального выгорания использовался метод ранговой корреляции Спирмена.

\section{РЕЗУЛЬТАТЫ ИССЛЕДОВАНИЯ И ИХ ОБСУЖДЕНИЕ}

Проанализировав опросник MBI, получили результаты, представленные в таблице 2. По шкале «Эмоциональное истощение» показатели среднего арифметического во всех трех группах относятся к высокому уровню (от 28,4 $\pm 5,2$ до $31,6 \pm 4,4)$, который проявляется в переживаниях сниженного эмоционального тонуса, повышенной психической истощаемости и аффективной лабильности, утраты интереса и позитивных чувств к окружающим, ощущении «пресыщенности» работой, неудовлетворенностью жизнью в целом.

Показатели среднего арифметического по шкале «Деперсонализации личности» во всех обследованных профессиональных категориях относятся к высокому уровню (от 17,4 $\pm 2,5$ до $19,6 \pm 4,6)$, проявляющемуся в эмоциональном отстранении и безразличии, формальном выполнении профессиональных обязанностей без личностной включенности и сопереживания, а в отдельных случаях - в негативизме и циничном отношении. На поведенческом уровне «деперсонализация» проявляется в высокомерном поведении, использовании профессионального сленга, юмора, ярлыков.

По шкале «Профессиональная успешность» результаты врачей относятся к высокому уровню $(37,9 \pm 2,1)$, показатели медсестер $(35,1 \pm 2,2)$ и санитарок $(33,75 \pm 0,3)$ - к среднему уровню. Таким образом, по данной шкале результаты медицинских работников благополучнее остальных шкал, однако именно по данной шкале между профессиональными группами существуют различия $(\mathrm{n}=150 ; \mathrm{H}=10,01 \mathrm{p}=0,02)$. 
Значения показателей опросника MBI для разных категорий медицинских работников противотуберкулезных учреждений

\begin{tabular}{|l|c|c|c|}
\hline \multirow{2}{*}{\multicolumn{1}{|c|}{ Субшкала }} & \multicolumn{3}{|c|}{ Категории (профессии) медицинских работников } \\
\cline { 2 - 4 } & $\begin{array}{c}\text { врач } \\
(\mathrm{n}=17)\end{array}$ & $\begin{array}{c}\text { медсестра } \\
(\mathrm{n}=79)\end{array}$ & $\begin{array}{c}\text { санитарка } \\
(\mathrm{n}=54)\end{array}$ \\
\hline Эмоциональное истощение (в ед.) & $31,6 \pm 4,4$ & $28,4 \pm 5,2$ & $29,3 \pm 3,1$ \\
\hline Деперсонализация (в ед.) & $17,4 \pm 2,5$ & $18,1 \pm 3,8$ & $19,6 \pm 4,6$ \\
\hline Профессиональная успешность (в ед.) & $37,9 \pm 2,1^{*}$ & $33,8 \pm 0,3^{*}$ & $35,1 \pm 2,2^{*}$ \\
\hline
\end{tabular}

Примечание: * ${ }^{*} \mathrm{p}<0,05$.

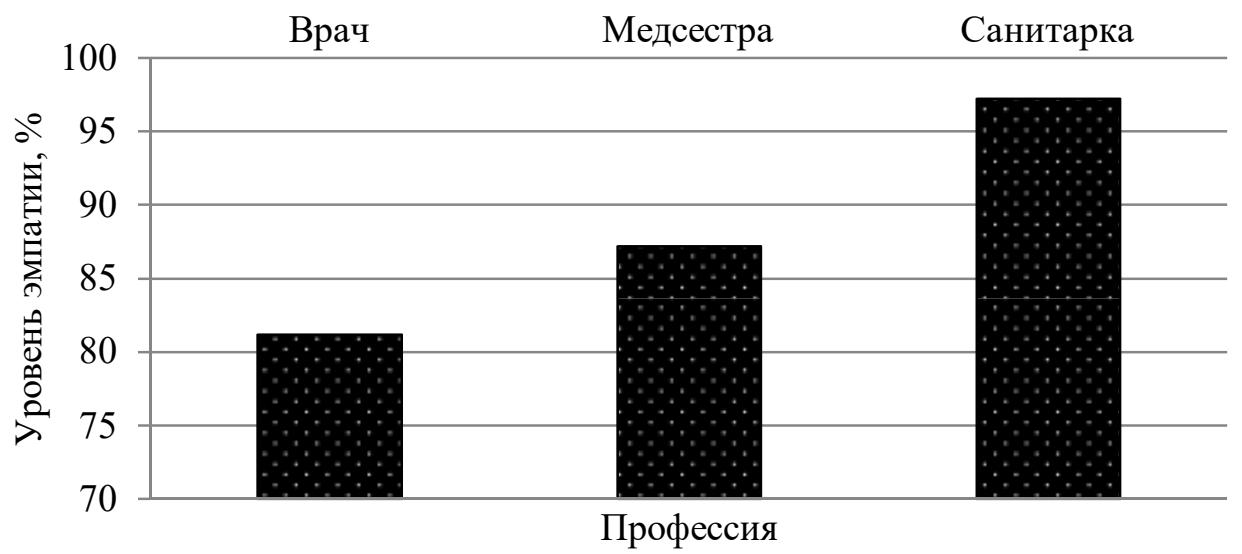

Рис. 1. Уровень эмпатии медицинских сотрудников.

Редукция личностных достижений является последней стадией в трехмерной модели (К. Маслач и С. Джексон) выгорания специалистов и проявляется в тенденции негативно оценивать плоды своей деятельности. В данном случае редукция личностных достижений может проявляться в тенденции заниженной самооценки и оценке своей профессиональной деятельности или ограничении своих возможностей и обязанностей по отношению другим людям.

В отличие от редукции личностных достижений, значения уровня эмпатии (рис. 1) выглядят диаметрально противоположно: самый высокий уровень эмпатии оказался у санитарок $(97,28 \pm 4,55)$ и медсестер $(87,2 \pm 3,51)$, а самый низкий у врачей $(81,18 \pm 1,72)$. Возможно, это связано с тем, что большую часть времени именно санитарки и медсестры находятся в непосредственном контакте с пациентами и более сочувственно относятся к физическому состоянию больных. В целом по результатам нашего исследования уровни эмпатии $\mathrm{y}$ медицинских сестер и санитарок относятся к «очень высокому», в то время как у врачей - к «высокому».

U-критерий Манна-Уитни (рис. 2) показал статистически значимые $(\mathrm{p}=0,008)$ различия в эмоциональном истощении между сотрудниками КУЗОО КПТД и КУЗОО КПТД № 4, уровень истощения сотрудников КУЗОО КПТД № 4 оказался выше на 50\%, что может быть связано с преобладающим контингентом пациентов. Так, впервые выявленные больные туберкулезом и диагностические пациенты (среди которых достаточно большой процент социально сохранных людей) направляются преимущественно в КУЗОО КПТД. В то время как в КУЗОО КПТД № 4 находятся больные с сочетанной патологией (ВИЧ-ассоциированный туберкулез, МЛУ-туберкулез, туберкулез в сочетании с сахарным диабетом и др.), генерализованным туберкулезом, туберкулезом ЦНС, пациенты, направленные на хирургическое лечение, включая больных с фибрознокавернозным туберкулезом, также в стационаре есть отделение для оказания помощи больным с хроническими формами туберкулеза и различными, включая эмпиемы плевры, осложнениями, которые по тяжести состояния требуют больших эмоциональных затрат.

По остальным шкалам статистически значимых различий между КУЗОО КПТД и ПТД № 4 не выявлено.

Также было изучено влияние эмпатии на уровни профессионального выгорания. Как видно из рисунка 3 , существует прямая связь $(\rho=0,34$ при $\mathrm{p}=0,000059)$ между профессиональной успешностью и эмпатией. Как было сказано ранее, при возрастании эмпатии снижается редукция личностных достижений. 


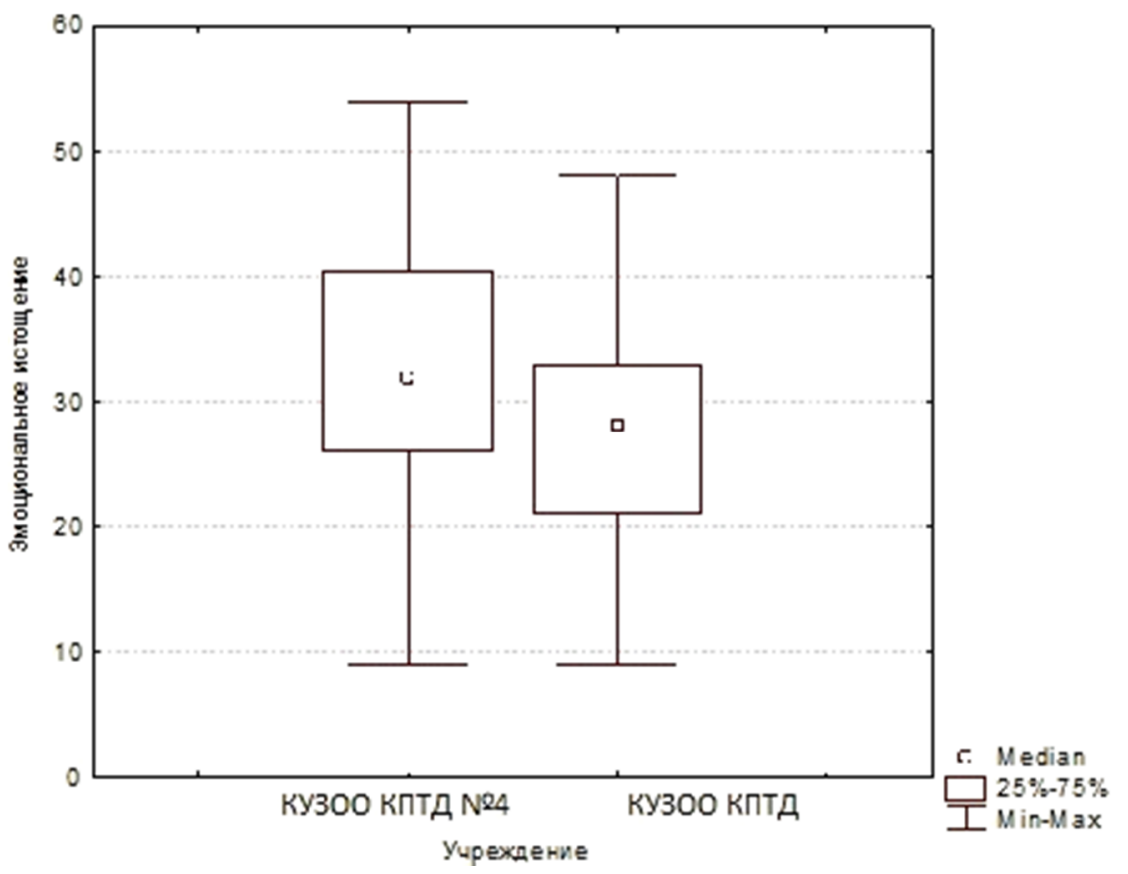

Рис. 2. Эмоциональное истощение среди медицинских работников КУЗОО КПТД и КУЗОО КПТД № 4.

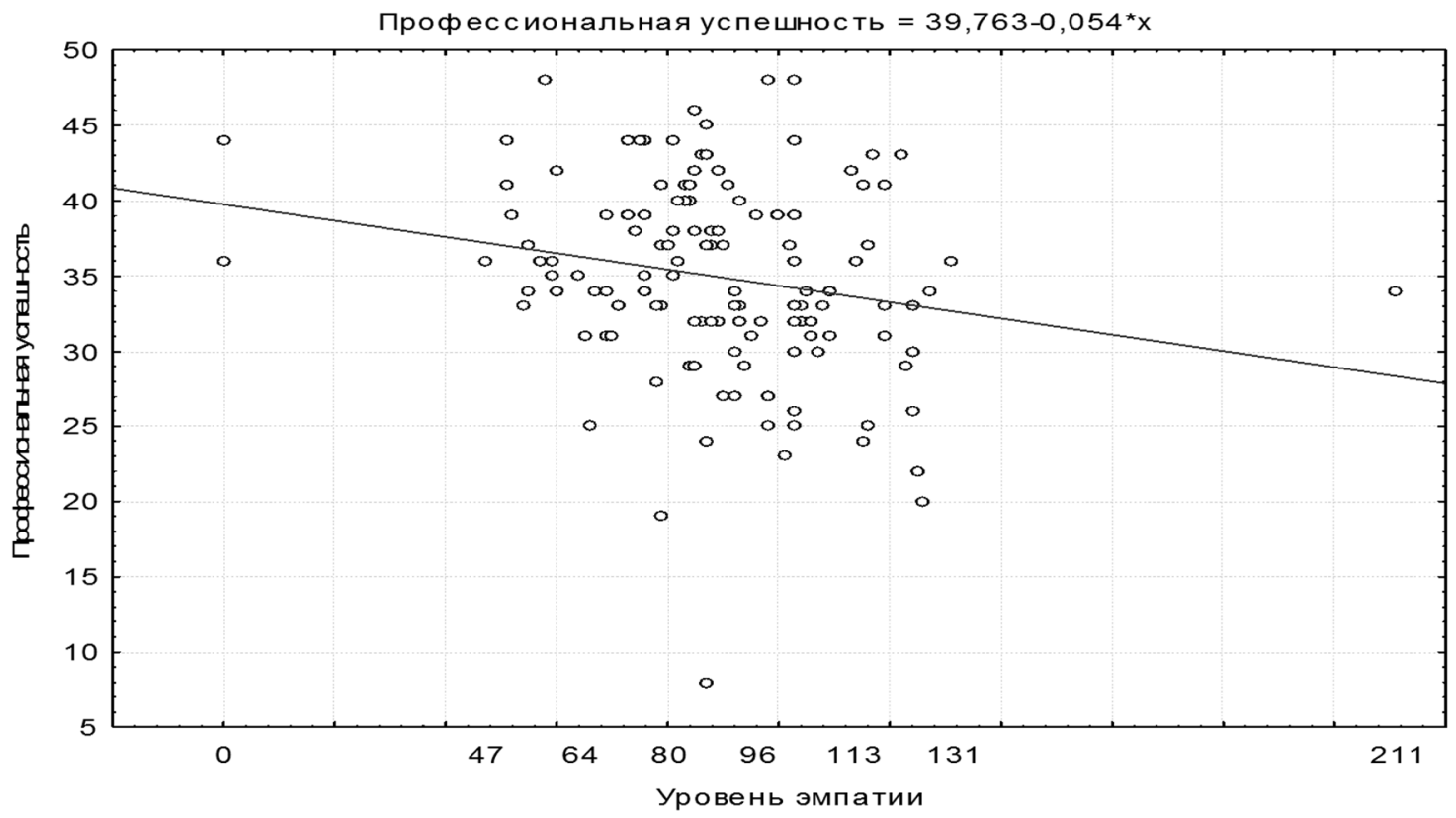

Рис. 3. Взаимосвязь эмпатии и профессиональной успешности (редукции личностных достижений).

В деперсонализации личности (рис. 4) выявлена обратная корреляционная связь от эмпатии $(-3,2$ при $\mathrm{p}=0,002)$. При возрастании эмпатии увеличивается уровень деперсонализации личности, то есть происходит восприятие собственной личности как бы со стороны с невозможностью управлять собственными действиями. Слабая корреляционная связь говорит о слабом проявлении данного признака и может диагностироваться только в клинических условиях.

Между стажем трудовой деятельности и возрастом сотрудников корреляция со значением уровня эмпатии и субшкалами профессионального выгорания оказалась низкой и не достоверной.
Данный факт может говорить о предрасположенности людей к данной профессии и личностных особенностях специалистов, работающих в данной сфере.

В исследовании выявлено влияние профессии (врач, медицинская сестра, санитарка) на уровень редукции личностных достижений (профессиональной успешности): самый низкий показатель профессиональной успешности установлен у санитарок, средние его значения у медсестер, высокие у врачей. Способность сопереживать или самый высокий уровень эмпатийных тенденций оказался у санитарок, более низкие его значения отмечены у врачей и медицинских сестер. 


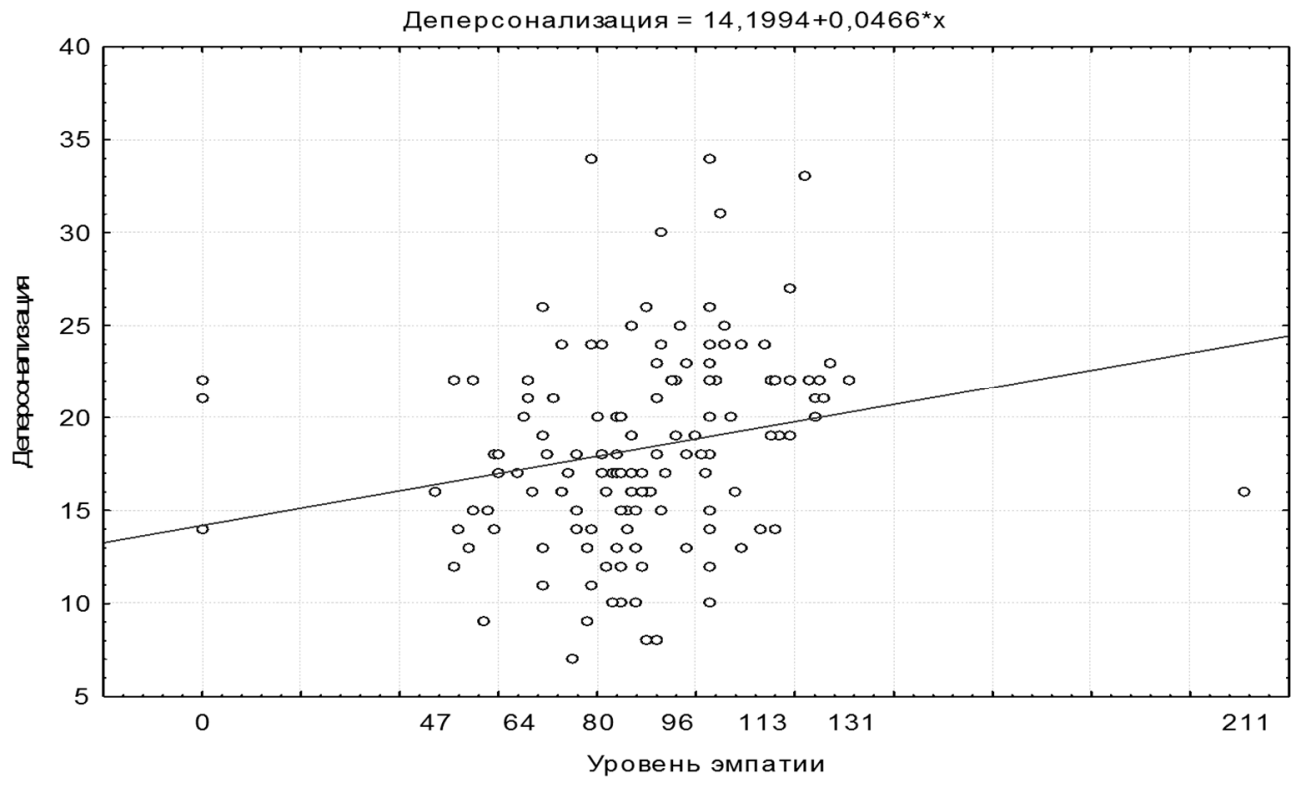

Рис. 4. Взаимосвязь эмпатии и деперсонализации личности.

Работа санитарки в противотуберкулезном учреждении крайне сложна, уход приходится осуществлять не просто за опасными в эпидемиологическом плане пациентами, а за лицами, часто являющимися не только социально дезадаптированными, но и относящимися к категории социопатов $[8,9]$. Только при наличии высокого уровня эмпатии можно успешно осуществлять свою деятельность в таких условиях. При сравнении значений показателя эмпатии у врачей и медицинских сестер они оказались отнесены к высокому уровню, вероятно, люди с низким уровнем эмпатийных тенденции не идут работать во фтизиатрию ввиду специфики контингента и деятельности $[10,15]$.

Высокий уровень эмпатии у медицинских работников препятствовал редукции их личностных достижений в сфере профессионального выгорания, однако он мог способствовать увеличению уровня деперсонализации личности. На уровень эмоционального истощения сотрудников достоверно влияет контингент пациентов противотуберкулезного учреждения. Больные туберкулезом, ассоциированным с ВИЧинфекцией, генерализацией специфического процесса на поздних стадиях ВИЧ-инфекции, доля которых увеличивается в последние годы [5, $10,14]$, хронизация и осложненное течение туберкулезного процесса у больных с длительно текущим туберкулезом $[1,12]$ создают определенные сложности в плане работы персонала, требующие повышенного внимания и приводящие к большему профессиональному выгоранию сотрудников соответствующего противотуберкулезного учреждения.

\section{ЛИТЕРАТУРА}

1. Бекмухамбетова Н.В., Иванова О.Г., Мордык А.В., Багишева Н.В. Некоторые особенности клинического течения туберкулеза органов дыхания и сопутствующей соматической патологии // Омский научный вестник. - 2014. - № 2. - С. 8-10.

2. Бохард А.К. Эмпатия в клиент-ориентированной психотерапии: сопоставление с психоанализом и Я-психологии // Иностранная психология. - 1993. - № 1. - С. 27-29.

3. Водопьянова Н.Е., Старченкова Е.С. Синдром выгорания. Диагностика и профилактика. - СПб. : Питер: Питер-принт, 2005. - 336 с.

4. Галако Т.И., Асанбаева Э.М. Проблемы и последствия профессиональной деформации врача-психатра // Вестник Кыргызско-Российского славянского университета. - 2008. - Т. 8, № 5. C. 104-106.

5. Коломиеи В.М., Гусева В.А., Рублева Н.В., Шахова Ю.И. Особенности клинического течения и лечения ВИЧ-ассоциированного туберкулеза // Курский научно-практический вестник «Человек и его здоровье». - 2012. - № 1. - С. 142-147.

6. Купирякова Ю.А. «Синдром эмоционального выгорания» врачей как индикатор состояния российского здравоохранения // Социальная политика и социология. - 2011. - № 3. - С. 90-94.

7. Мальгин В.Л., Искандирова А.Б., Пахтусова Е.Е. Социальные и профессиональные факторы риска формирования выгорания у врачей-психиатров и наркологов // Прикладные информационные аспекты медицины. - 2008. - № 11. - С. 71-75.

8. Мордык А.В., Брюханова Н.С., Антропова В.В., Пузырева Л.В. Роль личности пациента в процессе выявления и лечения туберкулеза органов дыхания // Кубанский научный медицинский вестник. 2011. - № 4. - C. 148-151.

9. Мордык А.В., Пузырева Л.В., Подкопаева Т.Г. Социальный статус пациентов противотуберкулезного диспансера и его влияние на отношение к 
лечению // Социология медицины. - 2011. - № 2. C. 44-47.

10. Мордык А.В., Удалова Т.Ю., Пузырева Л.В., Леденева Т.Н., Ситникова С.В. Сравнение личностных особенностей больных с впервые выявленным инфильтративным туберкулезом легких и сочетанной инфекцией ВИЧ/туберкулез // Бюллетень сибирской медицины. - 2015. - Т. 14, № 1. C. 60-65.

11. Поркулевич Н.И., Мордык А.В., Гурова Я.В., Мартынова Г.Г. Анализ причин формирования фиброзно-кавернозного туберкулеза // Туберкулез и болезни легких. - 2015. - № 5. - С. 154-155.

12. Романов С.Н., Николаев Е.Л., Голенков А.В. Сравнительное исследование адаптивных характеристик личности у студентов и врачей // Вестник
Чувашского университета. - 2012. - № 3. C. 469-473.

13. Ситникова С.В., Мордык А.В., Иванова О.Г. Влияние ВИЧ-инфекции на результаты стационарного курса лечения больных с ассоциированной патологией туберкулез/ВИЧ-инфекция // Туберкулез и болезни легких. - 2015. - № 7. - С. 128-129.

14. Ситникова С.В., Удалова Т.Ю., Мордык А.В. Учет личностных особенностей больных с сочетанием туберкулеза и ВИЧ-инфекции при организации процесса лечения // Туберкулез и болезни легких. - 2015. - № 7. - С. 129-131.

15. Duan C., Hill C.E. The Current State of Empathy Research // Journal of Counseling Psychology. 1996. - Vol. 43, N 3. - P. 261-274. 